\title{
EL RULE OF LAW COMO IDEA DE SOCIEDAD
}

\section{Francesco Viola}

Universidad de Palermo (Italia)

francesco.viola@unipa.it

Recibido: $18 / 05 / 2020$

Aceptado: 30/05/2020

\section{Resumen}

Como es bien sabido, el rule of law, que hoy atrae una atención renovada, puede observarse desde múltiples puntos de vista, lo cual produce ambigüedad y malentendidos. Parece prometer más de lo que puede cumplir. No me ilusiono con que mis escritos sobre el tema sean útiles para su mejor comprensión y realmente espero que no hayan contribuido en su pequeñez a agitar aún más las aguas. ${ }^{1}$ Por esta razón, agregaré otras consideraciones de carácter más general, orientadas a incluir la problemática del rule of law en el contexto más amplio de una concepción del derecho. Si se mira a la distancia, las cosas se ven con menos claridad, pero se ven más y, sobre todo, en su interconexión e interdependencia. En cualquier caso, me parece evidente que la fórmula del rule of law no se explica por sí misma, sino que su sentido depende de una presupuesta concepción del derecho.

Palabras clave: rule of law, interpretación, contexto, amplitud, derecho, justicia.

\section{The Rule of Law as an idea of society}

\begin{abstract}
The Rule of Law must not be understood exclusively as a set of formal requirements, but also as a way of understanding the concept of law and legal theory, and more generally as a social practice that makes possible the respect of legal validity. Nevertheless, the Rule of Law does not meet all the components of the idea of law. Positive law claims to be right in content, even if this claim is not always satisfied. The Rule of Law and the claim of justice are necessary and ideal requirements of the concept of law.
\end{abstract}

Key words: concept of law, rule of law, idea of law, legal theory, justice.

* Traducción del italiano al español realizada por la Prof. Dra. María del Rosario Stoppani (Universidad Austral).

1 He recopilado estos escritos que aquí presupongo en Viola (2011). 


\section{Las razones del rule of law}

Desde el punto de vista de la teoría y de la filosofía del derecho, que considero inescindibles en la medida en que están unidas en la búsqueda de la naturaleza del derecho mediante juicios de relevancia cuyo carácter filosófico es ineliminable, surge el problema del lugar que en ellas tiene el rule of law.

Todos reconocen que el objetivo del rule of law es evitar la arbitrariedad del poder tanto como sea posible. ${ }^{2}$ Esto se concentra simplemente en dos prescripciones: $^{3}(1)$ cualquier forma de uso del poder -ya sea vertical, es decir, propia de la autoridad política; ya sea horizontal, o sea, de otros individuos y grupos sociales- debe ser ejercido de alguna manera en las formas del derecho y limitado por ellas; ${ }^{4}$ y (2) el derecho debe ser capaz de guiar la acción humana. Por lo tanto, el rule of law se refiere conjuntamente al poder y al derecho, al ejercicio del poder y al modo de ser del derecho. Sin embargo, no creo que el rule of law esté directamente dirigido también contra la anarquía, como algunos sostienen, ${ }^{5}$ porque para evitar esto son más efectivos los métodos policiales. El mal político que el rule of law combate es propiamente la arbitrariedad entendida en un sentido específico. ${ }^{6}$ El bien moral que defiende es aquel que hace a los actos de la autoridad razones para la acción humana; además, en general, protege a los individuos de la interferencia arbitraria de otros. En consecuencia, las reglas jurídicas deben poder ser seguidas por seres racionales capaces de realizar una actividad de deliberación y de elección. Por lo tanto, se excluye que estas reglas sean entendidas en modo causal (o mecánico) para determinar el comportamiento de los destinatarios. Por el contrario, estas deben ser capaces de "guiar" el comportamiento humano, para lo cual deben proporcionar razones que justifiquen de alguna manera su pretensión de obediencia. De estas complejas exigencias surge la fórmula del rule of law.

Conducir una acción humana es algo muy diferente a causarla o producirla.

2 Cfr. Tamanaha (2004).

3 Damos aquí, aunque no todos están de acuerdo, una versión muy ampliada de rule of law en vista de nuestro objetivo, que es ver en él una idea general de asociación humana.

4 No solo no debe identificarse la autoridad política con la autoridad estatal, lo que también es evidente en la frecuente referencia al rule of law por el derecho de la Comunidad Europea, sino que también se la debe extender de alguna manera a otros ordenamientos específicos de las relaciones humanas no directamente "políticas", como a las organizaciones internacionales, al gobierno mundial de la economía y, en última instancia, a todas las relaciones sociales que impliquen el uso de poder del hombre sobre el hombre.

5 Cfr., por ejemplo, Fallon (1997, p. 7).

6 La arbitrariedad debe distinguirse de la discrecionalidad, que es inevitable en las decisiones de la autoridad. Sin discrecionalidad, no hay autoridad. 
Para el concepto de derecho, el modo de la obediencia a él es al menos tan importante como el hecho de la obediencia. Por ello, resultan inadecuadas todas aquellas concepciones del derecho que se refieren exclusivamente a su capacidad para poner orden en la sociedad o a la eficacia de sus resultados a los fines de la coordinación social. Definir, por ejemplo, al "derecho" como ese conjunto de órdenes del soberano que reciben una obediencia habitual (Austin) significa eliminar de su concepto la pretensión de dar razones para la acción. Los esclavos obedecen las órdenes de los patrones y generalmente lo hacen de manera habitual. ${ }^{7}$ Incluso referirse a la aceptación práctica de las reglas por parte de funcionarios o ciudadanos (Hart) no es aún suficiente si esta aceptación no está respaldada por razones en sentido propio o verdaderas.

El derecho no está dirigido a ordenar a la sociedad de cualquier manera, sino que busca hacerlo de un modo específico: el de la coordinación de las acciones de agentes racionales que, en cuanto tales, necesitan razones para actuar en la vida social. "Dirigir una acción" se refiere no solo al modo en el que la autoridad dirige las acciones de aquellos que están sujetos a ella, sino también al modo en que estos se gobiernan a sí mismos. De hecho, este segundo sentido es prioritario, ya que permite que agentes libres y conscientes puedan conservar y ejercer las propias prerrogativas morales que la autoridad debe gobernar mediante el derecho. El derecho tutela la posibilidad del obrar moral en la vida social. Sin este presupuesto, el derecho mismo pierde su especificidad con respecto a otros métodos de control social. El puesto de los legisladores, jueces y juristas puede ser ocupado sin consecuencias por los gerentes, psiquiatras y tecnócratas (Fuller, 1969, p. 38).

Por lo tanto, creo -como he intentado mostrar en otra parte- que no se debe negar que el rule of law pertenezca de manera estricta y esencial al concepto de derecho. Ciertamente, se puede negar (y ha sido negado con autoridad), pero con la condición de considerar al derecho como un conjunto de reglas sociales tomadas estáticamente y no como un conjunto de actividades guiadas por reglas. Pertenece, de hecho, al concepto mismo de regla social el conjunto de las condiciones que permiten la practicabilidad. Como hemos aprendido de Wittgenstein, una regla es tal si puede ser seguida como tal.

La formulación del rule of law tiene siempre un carácter histórico y contingente, porque las formas de arbitrariedad posibles están ligadas a la configuración histórica del poder. Los desiderata de Fuller (1969) son, por un lado, una

7 Según Tomás de Aquino, el carácter propio de la ley es dirigir la acción (lex omnis directiva est actuum humanorum). Su vis coactiva es secundaria respecto a su vis directiva. Cfr., por ejemplo, Summa theologiae, I-II, q. 95, a. 1. 
formulación canónica mínima y, por otro, históricamente condicionados por la centralidad de la ley general y abstracta. Se puede pensar, por ejemplo, que en el ámbito del constitucionalismo contemporáneo el control judicial de constitucionalidad pasa a ser parte del rule of law, pero esto es controvertido; ${ }^{8}$ o se puede preguntar cuál debe ser la formulación actual de un rule of international law. En todo caso, la configuración del rule of law debe mantener un carácter elástico y flexible, capaz de adaptarse a los cambios de la cultura jurídica y a las metamorfosis del poder. Pero sobre esto no nos detendremos.

\section{El rule of law y la validez del derecho}

Si el rule of law pertenece al concepto de derecho, entonces debe también considerarse que un capítulo central de la teoría del derecho debe referirse al problema de la obediencia y al de la obligatoriedad del derecho. No puede separarse una investigación sobre la naturaleza del derecho de aquella sobre su fuerza justificativa, de lo contrario, hablar de "normatividad" no tendría sentido. En consecuencia, se necesitaría considerar como incompletas o insuficientes todas aquellas teorías que tienden a subestimar tal cuestión, reenviándola al campo moral o político. El derecho positivo pretende ser obligatorio de manera similar a la moral, tanto como para poder competir con ella. Hay una obligatoriedad que es propia del derecho en cuanto tal, incluso si esa puede ser solo prima facie.

En el intento de individualizar una definición del derecho, compartida o compartible por todos los principales defensores del iuspositivismo, John Gardner (2001, p. 199), cuya muerte reciente nos aflige, la expresa en términos de un concepto determinado de "validez" de las normas jurídicas, una validez estrechamente dependiente de las fuentes (entendidas en sentido amplio) y no del valor de su contenido. En su opinión, este concepto de derecho es completamente inerte en el nivel normativo, es decir, no tiene ningún rol de guía del comportamiento humano, no nos dice aquello que los destinatarios deberían hacer o no hacer, sino que solamente pone una condición que cada directiva jurídica en cuanto tal debe tener: aquella de ser válida solo en virtud de su origen y no de su contenido (Gardner, 2001, pp. 202-203). Pero de ese modo se intercambia una condición que todo aceptable concepto de derecho debe tener, es decir, hacer siempre referencia al derecho "puesto" con el concepto de derecho en cuanto tal. Gardner (2001) tiene cuidado de no caer en este equí- 
voco, pero lo evita solo afirmando que el iuspositivismo no es una completa teoría del derecho, sino solo una teoría de la validez del derecho. ${ }^{9}$ Sin embargo, tiene sentido hablar de iuspositivismo solo con la condición de identificar al derecho con su validez fáctica, de lo contrario, no se hace otra cosa que subrayar el necesario carácter de la positividad que toda concepción del derecho debe respetar de alguna manera.

¿En el concepto de derecho hay algo más que la mera positividad del derecho? Con respecto a esta pregunta, el iuspositivismo no puede declararse agnóstico sin renunciar a ser enteramente una teoría del derecho, porque es precisamente la respuesta a esta pregunta lo que lo caracteriza y lo distingue de las otras concepciones del derecho. Dado que, como hemos visto, el concepto de derecho también debe tener un carácter normativo, es decir, no ser normativamente inerte, se debe entonces explicar cómo algo "puesto" por los seres humanos puede ser guía del comportamiento humano, dando vida a derechos y obligaciones que pasan a ser parte de la deliberación moral.

Por otro lado, las dos condiciones del concepto de derecho -ser puesto y ser normativo- no son del todo independientes entre sí, ya que, como se ha dicho, las razones del derecho como artefacto consisten en guiar la acción de agentes racionales. En consecuencia, la misma positividad jurídica debe tener un carácter normativo. Este es el desafío que toda aceptable concepción del derecho no debe tratar de eludir, no puede superarse si se excluyen por completo del concepto de derecho consideraciones ligadas al uso de las proposiciones normativas y si estas son independientes del concepto de validez jurídica.

Por cierto, otra operación cultural de este tipo se encuentra en la separación de la problemática de la interpretación del derecho de la de su aplicación, ya que el carácter avalorativo de la primera es más fácil de sostener una vez liberada del necesario carácter valorativo de la segunda. Es un procedimiento típico de la ideología iuspositivista deshacerse de temas incómodos, esterilizando la teoría hasta el extremo de la teoría pura de Kelsen. Si solo los "hechos" pueden conocerse científicamente, los problemas que requieren recursos distintos de los hechos son etiquetados o como pseudoproblemas o como no pertenecientes a la teoría jurídica. ${ }^{10}$ Pero una teoría que no tiene en cuenta la fuerza obligatoria del derecho o de la estrecha conexión entre interpretación y aplicación es poco útil, además de muy poco interesante.

9 "Legal positivism is not a whole theory of law's nature, after all." (Gardner, 2001, p. 210)

10 Evidencio que también el deber ser kelseniano (Sollen) es concebido como un "hecho", aunque sea de una naturaleza particular. 
Entonces resulta evidente que la consideración del rule of law depende sobre todo del modo de entender las tareas y las finalidades de una teoría jurídica. Las elecciones del teórico sobre lo que debe ser considerado relevante para la formación del concepto de derecho condicionan el destino de la consideración del rule of law. Si lo que es estrictamente relevante es la cuestión de la validez de las normas jurídicas con base en sus fuentes (o a su pedigrí), entonces la cuestión del uso y de la práctica de las normas pasa a un segundo lugar. Por el contrario, la relevancia del rule of law requiere la superación de esta perspectiva. La cuestión de la validez de la norma surge solo después de haberse asegurado de estar frente a un sistema de reglas respetuosas del rule of law o, en general, de una forma de sociedad gobernada por el derecho. La validez proviene del derecho y no viceversa. La ley bien puede derivar su validez de una regla básica de reconocimiento -como nos ha enseñado Hart-, pero su carácter de derecho deriva del modo en que el sistema normativo, del cual forma parte la regla de reconocimiento, se aproxima a la idea de derecho. ${ }^{11}$ Esta es propiamente la base del deber de fidelidad al derecho por parte de los jueces y, en general, de los funcionarios del derecho. Sería muy reduccionista e inadecuado hablar de un deber de fidelidad a la validez del derecho, como lo hace el legalismo.

\section{El rule of law como idea del derecho}

De la premisa de que el rule of law es una propiedad esencial del concepto de derecho, de la constatación de que es normal que una teoría jurídica aspire a ser completa y que es defectuosa si está incompleta, y del agregado de que una teoría completa debe ocuparse de la obligatoriedad del derecho y de sus condiciones de practicabilidad deriva necesariamente que el concepto de derecho tiene un carácter normativo. Dentro del concepto de derecho está la idea a la que este debe adecuarse, lo que significa que el deber ser del derecho pertenece a su ser. Esto, en mi opinión, es suficiente para excluir al descriptivismo como un método adecuado para comprender la naturaleza del derecho. Una teoría del derecho tiene un carácter normativo en cuanto está comprometida a "describir" aquello que el derecho debería ser para ser reconocido como derecho.

Los conceptos de razón práctica son en realidad "ideas" sobre el modo correcto de realizar una acción. ${ }^{12}$ El derecho pertenece a la razón práctica a todos

11 Cfr. Simmonds (2017, p. 256).

12 La rígida separación entre concepto e idea se debe sobre todo al neokantismo y ha sido por ese aplicada también al derecho. El resultado, enfatizado por el neopositivismo, ha sido el de reservar 
los efectos, es una acción a realizar y la reflexión al respecto se refiere al modo más correcto y apropiado de ponerlo en práctica. ${ }^{13} \mathrm{Si}$ el derecho es un artificio, no se lo puede conocer apelando a los hechos o a los conceptos extraídos de él, como en las ciencias naturales. Solo se lo conoce observando las razones de por qué es bueno que exista y las formas más correctas de satisfacer tales razones. ${ }^{14}$

La precomprensión del derecho, propia del rule of law, consiste en una idea de sociedad o en una forma de asociación en la que las reglas, aunque siempre puestas por hombres, escapan a su poder arbitrario y constituyen un tejido social a cuya elaboración contribuyen todos, con diferentes roles, en un régimen cooperativo de mutua responsabilidad y de reciprocidad. Tal régimen es "confiable" y, por lo tanto, capaz de proporcionar razones no meramente formales que justifiquen la obediencia a sus preceptos. Esta idea se presenta, por lo tanto, como un ideal al cual los ordenamientos jurídicos concretos se aproximan en diferentes grados. Podemos también considerar esto como un ideal moral, siguiendo de alguna manera la "moralidad interna del derecho" de la que ha hablado Fuller (1969). Esta es bien reinterpretada en un sentido amplio por Postema (2014) cuando basa la fidelidad en el derecho no tanto en el respeto de requisitos formales, sino más bien en una forma de vida social marcada por la rectitud y por la reciprocidad, de modo que el rule of law se presente en la sustancia como una práctica social específica, un modo de entender la práctica del derecho, una ética del homo juridicus y de sus virtudes. En consecuencia, sobre este punto hay indudablemente una conexión entre derecho y moral, pero ya no a nivel del contenido de las normas jurídicas, sino a nivel de las formas de la vida práctica en cuestión. La idea del derecho pertenece en general a la forma de la moralidad, de modo que el posible conflicto entre derecho y moral, entre lo que es legal y lo que es justo, debe entenderse como algo interno a la moralidad misma, es decir, es un conflicto de valores conmensurables en tanto pertenecientes a la misma familia. No sería así si el derecho fuera una mera técnica de control social. En este caso, no se podría hablar ni de obligatoriedad ni de conflicto de valores. La técnica funciona o no funciona.

toda verdadera y propia capacidad cognitiva al campo teorético, abandonando lo práctico al reino de las emociones y las ideologías. Sobre esta problemática, cfr. Viola (2016b, pp. 14-19).

13 Particularmente sensibles a este aspecto han sido, como se ve, las teorías francesas de la institución, pero aquí no se quiere defender ninguna concepción específica de la idea de acción.

14 Cfr. Finnis (2003, pp. 107-129). 


\section{Dos caminos en la formación del concepto de derecho}

Tratemos ahora de imaginar cómo debería entenderse un concepto de derecho que sea "práctico" en el sentido ya dicho, es decir, cómo podemos configurar una posible concepción del derecho que sea respetuosa de las presuposiciones ya mencionadas. ¿Cuáles deberían ser los siguientes pasos? ¿Qué lugar y qué función tendría en ella el rule of law? También sobre la base de las exploraciones ya cumplidas y de las presuposiciones ya formuladas podemos plantear como hipótesis dos posibles caminos teóricos, efectivamente practicados por algunos teóricos del derecho. Ambos reconocen que el rule of law es parte del concepto de derecho, pero difieren, entre otras cosas, en el rol que este desempeña.

El primer camino sostiene que la tarea principal del teórico del derecho es configurar un concepto pleno de derecho que constituya el caso ejemplar, a modo de individualizar el significado focal del derecho (focal meaning). Sobre la base de este modelo, que no es ideal porque se basa en lo que una persona prácticamente racional debería pensar sobre el rol del derecho en los asuntos humanos, es posible medir los casos faltantes, defectuosos o desviados. Sin embargo, estos casos pertenecen al derecho en la medida en que se conserva la analogía del concepto. El derecho es un concepto analógico en el sentido de la tradición escolástica, es decir, opuesto a la lógica unívoca y esencialista de la analytic jurisprudence. El caso ejemplar es su analogado principal, aquel en el que el concepto se realiza en toda su plenitud, mientras que los casos defectuosos son los analogados secundarios hasta un cierto umbral, por debajo del cual no hay derecho. ${ }^{15}$

Si luego nos preguntamos sobre el modo de entender este "caso ejemplar" de derecho, debemos reconocer que su configuración depende de una filosofía moral y política presupuesta, encarnada por la persona "prácticamente racional” en la que se inspira el teórico. El derecho no es una isla y es en vano pretender comprenderlo en su aislada y estéril pureza. Un ejemplo (pero no el único posible) de un "caso ejemplar" es dado por Finnis (2011, p. 418), quien recurre a los principios de la razonabilidad práctica (o de derecho natural) que son necesarios para justificar la legitimidad de la autoridad y su ejercicio en el respeto de los derechos humanos y del bien común, así como en la observancia general del rule of law. Todo se articula por el razonamiento práctico. En esta perspectiva, el rule of law es solo un aspecto del concepto de derecho o una de las propiedades que caracterizan el sentido focal de derecho. Su función no es

15 Se habrá reconocido fácilmente en este esquema la teoría del derecho de John Finnis, que aquí utilizo solo como ejemplo. 
señalar los valores centrales del derecho, sino poner en posición de participar a aquellos de manera consciente y cooperativa; es decir, hacer bien el bien. Sin embargo, estas propiedades del concepto de derecho no deben ser tratadas como aspectos separados, porque el modo de hacer el bien pertenece al concepto que contiene al bien, como se evidencia en el hecho de que el respeto de los principios del rule of law es el respeto de los derechos que pertenecen a los fines mismos del derecho y de su justicia. Es decir que en el caso ejemplar de derecho, el rule of law asume por contagio un sentido sustancial que lo rescata del mero legalismo. ${ }^{16}$

El segundo camino posible de la formación del concepto de derecho va en la dirección opuesta. No se trata de aspirar a un concepto completo (wide concept of law), sino a un concepto mínimo (narrow concept of law), es decir, a la individualización del caso más elemental de derecho. Es la línea de pensamiento seguida por Fuller (1969) y desarrollada, entre otros, por Simmonds (2007), a cuyo pensamiento haremos referencia directa. Nuestro conocimiento del derecho comienza con la consideración de prácticas establecidas, aun entendidas confusa e indistintamente, pero designadas por la fórmula del rule of law, que es aquella expresada por Fuller (1969), aunque de manera contingente y revisable. Este modelo arquetípico mínimo y provisorio, que ya es un ideal moral -porque, como hemos visto, refleja una forma de asociación humana-, es el de la legalidad, que se distingue bien del de la justicia. La reflexión jurídica, aquella de la ciencia y de la teoría del derecho que son también formas de reflexión moral, enriquece además este elemental concepto de derecho sobre la base de las circunstancias históricas, de los contextos particulares en los que toma forma y se concretan la justicia y el bien común propios de una determinada sociedad. El resultado final será el de un concepto pleno o menos magro de derecho. Además, la tasa de juridicidad siempre se mide sobre la base del rule of law, cuyas características no tienen que estar todas necesariamente presentes en cada caso y son susceptibles de ser satisfechas con diversos grados de intensidad. Por lo tanto, aquí también el rule of law no debe ser identificado con la óptica positivista de la validez, pero también surge el problema del umbral mínimo de satisfacción de sus requisitos.

Una de las ventajas reclamadas por los partidarios de esta línea de pensamiento es la de exhibir un concepto de derecho que puede ser aceptado por

16 Es sabido que Kelsen (1952) expande drásticamente la teoría del rule of law desde la doctrina pura del derecho, es decir, desde el objeto de la ciencia jurídica, considerándola como "un prejuicio iusnaturalista” (p. 147). 
todos, es decir, incluso por los iuspositivistas, porque no depende de una determinada concepción de la moral (como en el caso del concepto pleno). Se cree que una vez aceptado este modelo, seremos inducidos a admitir la entrada de la moral en el derecho y sus inevitables consecuencias. El iuspositivista deberá cambiar de opinión. Pero, en realidad, no fue así, como lo demuestra la conocida polémica entre Hart y Fuller, concluida con la victoria provisoria del primero. De hecho, el verdadero obstáculo no consiste en la plausibilidad de este concepto mínimo de derecho, sino en entenderlo como un verdadero y propio ideal moral autosuficiente o, más correctamente -como Fuller parece entenderlo a veces-, como un ideal que conduce a asegurar, al menos en grado mínimo, la justicia del ordenamiento jurídico. Es cierto, como ha señalado Hart, que el rule of law es compatible con una gran injusticia, aunque es igualmente cierto que la justicia jurídica no es compatible con una grave violación de los requisitos del rule of law. En resumen, el rule of law parece ser una condición necesaria, pero no suficiente, de la justicia jurídica.

\section{El rule of law como ideal político}

Si ahora admitimos que el rule of law es una idea moral, queda aclarar en qué consiste esta. Según Simmonds (2007), combate la sumisión a la voluntad de los demás y, en consecuencia, defiende el valor de la libertad en el sentido kantiano de una coordinación de las libertades en un orden jurídico. Por lo tanto, esta idea moral está vinculada a un ideal político, que es el del liberalismo. Por ello, la concepción de Simmonds (2007) se acerca mucho al modo en el que Hayek (1960) ha tratado el rule of law. ${ }^{17}$ Pero, estrictamente, ver en el rule of law el ideal de la libertad política en su plenitud es excesivo, incluso considerándola en el modo amplio de un estilo de vida social, es decir, en la forma en que Postema (2014) la ha oportunamente retratado (fidelity thesis). En el fondo, aunque bajo ciertas condiciones, permanece la sumisión a la voluntad de otros, porque las leyes son siempre hechas por los hombres. Lo que se quiere evitar no es la sumisión, sino la arbitrariedad, es decir, el estar a merced de los otros, ya que ofrecer razones para la obediencia significa por parte del legislador $-y$, en general, de la autoridad- la responsabilidad de rendir cuentas. ${ }^{18}$

17 Hayek (1960, p. 206) ha contribuido poderosamente a acreditar la idea de que el rule of law es un ideal político, un baluarte indispensable de la libertad personal amenazada por el welfare state y por un gobierno administrativo.

18 Como señala Postema (2014), el poder arbitrario no es necesariamente ejercido de manera irracional 
En mi opinión, el rule of law asegura solamente la libertad juridica, que es precisamente la libertad de no estar a merced de los funcionarios públicos y no la libertad de tener tantas opciones de elección como sea posible. ${ }^{19}$

Como bien señala Simmonds (2007), el hombre libre se distingue del esclavo no por tener más posibilidades de elección, sino por poder elegir en sentido propio, deliberando sobre las razones de la acción. Pero de esto se deduce no solo que la libertad jurídica debe distinguirse de la libertad personal, de modo que la acción de gobierno no debe invadir todos los espacios de la autonomía personal, sino también que no coincide con la libertad política, en la cual los ciudadanos participan de alguna manera en la producción de las normas a las que están sujetos (self-rule). ${ }^{20}$ En rigor, puede haber libertad jurídica en regímenes iliberales y antidemocráticos. Sin embargo, la fórmula canónica del rule of law empuja ciertamente hacia la independencia del poder judicial y, por lo tanto, hacia una ampliación de los desiderata que incluye al menos la separación de poderes. Se podría también pensar que los principios del Estado constitucional de derecho no son más que una lógica expansión de las finalidades del rule of law, como por ejemplo la rigidez de la constitución, la reserva de ley o de la jurisdicción, el favor libertatis, la presunción de inocencia y la determinación taxativa de los casos en los que los derechos pueden ser limitados (por ejemplo, razones de orden público y de sanidad). Pero todos estos desarrollos de la fórmula del rule of law son posibles solo después del advenimiento de los regímenes constitucionales, de la constitucionalización de la persona, del reconocimiento de los derechos. Sucedió algo fuera del rule of law que puso en marcha su ulterior desarrollo. Esta constatación, en mi opinión, es una clara confirmación de que el rule of law es una idea que tiene como objetivo dar forma -la forma de legalidad- a lo que va acaeciendo en la vida social y política. El rule of law no es la causa de estas conquistas de civilización, sino un factor de estabilización o de gobierno de ellas.

En estas condiciones, el rule of law debe entenderse como un ideal jurídico a todos los efectos y no como ideal político, ya que es un aspecto del concepto de derecho que no tendría sentido fuera del derecho. Es lo más "jurídico” que

e imprevisible, pero sí es sobre todo el que no debe rendir cuentas.

19 Según Kelsen (1998, pp. 354-361), está fuera de lugar invocar el rule of law como garantía de la libertad del ciudadano, porque una legislación, respetuosa de las características antes mencionadas, puede ser tan intrusiva como para limitar en gran medida la libertad de acción.

20 Cfr., por ejemplo, Viola (2005, pp. 31-55). El ideal del law-rule como self-rule hace indudablemente del rule of law un ideal politico. Cfr. Michelman (1988, pp. 1500-1503). 
hay en el derecho, pero, al mismo tiempo, nos dice que en el concepto de derecho, o en la naturaleza del derecho, hay algo más. Se trata de un ideal jurídico en un sentido fuerte: tanto porque es estructuralmente interno -como ya se ha dicho- al concepto de derecho, como porque está dirigido a la expansión de la práctica jurídica y de sus garantías por debajo y por encima del Estado, que es una institución jurídica contingente. El respeto de los principios del rule of law a menudo se considera un paso necesario en el camino hacia las reformas políticas y sociales, ${ }^{21}$ pero esto no significa que se trate de un ideal político, sino solo que la libertad jurídica, aunque no sea la plenitud de la libertad social en todos sus aspectos más relevantes, es un componente necesario. Además, debe reconocerse, como mencionaremos seguidamente, que el valor de la libertad en sí mismo no es suficiente para agotar todas las aspiraciones del derecho.

Que el derecho sea artefacto no significa que esté esencialmente ligado al poder político o a las funciones de gobierno de la sociedad. La formación social de reglas jurídicas o de formas compartidas de hacer las cosas está ya suficientemente justificada por la exigencia de orientarse en la vida social y de desarrollar, en la medida de lo posible, los propios planes de vida en una sociedad en la que las expectativas están tuteladas y los compromisos se mantienen. ${ }^{22} \mathrm{La}$ prevalencia del principio de soberanía estatal llevó a comprender el rule of law como "gobierno de la ley" y a identificarlo con el principio de estricta legalida$\mathrm{d},{ }^{23}$ pero eso es reduccionismo desde múltiples perfiles.

Ante todo, la ley no es la única forma de prescripción jurídica, ya sea porque un sistema jurídico también contiene prescripciones particulares como porque todavía existen, hoy más que nunca, normas jurídicas que no son producidas por el Poder Legislativo ordinario, entre las cuales se hallan los principios jurídicos, que, como es sabido, en la época actual de constitucionalización del derecho asumen una importancia cada vez mayor. Se debe considerar que el rule of law debe ocuparse de todas las formas de normatividad jurídica, porque todas concurren a guiar el comportamiento social. Pero cada una de ellas debe ser tratada de acuerdo con su especie y sobre la base de las amenazas a la libertad jurídica que pueden provenir de ella, es decir, del uso arbitrario del poder que cada una hace posible. Hoy, como ya se ha señalado, ciertamente hay que

21 Para una crítica de esta creencia, cfr. Silverstein (2003, pp. 427-445).

22 Es interesante observar la reciente aplicación del rule of law a la gestión de los "bienes comunes", es decir, fuera de una dimensión estrictamente política. Cfr. Viola (2016a, pp. 381-398).

23 Aquí es necesario recordar la doctrina alemana del Rechtsstaat y el carácter expansivo que la forma de la ley ha asumido allí. 
hablar de un constitutional rule of law que internalice los métodos interpretativos de los tribunales constitucionales, como -el primero entre todos- el principio de razonabilidad, que por cierto no es ajeno a la tradición jurídica. ${ }^{24}$

\section{El rule of law y la pretensión de justicia}

Si ahora volvemos a meditar en los dos caminos de la formación del concepto de derecho y en sus diferentes formas de tratar el rule of law, se observa la diferencia entre la propuesta del caso ejemplar -el cual, sin duda, presenta el derecho como modelo moral y de la moral, completo en sí mismo- y la del caso elemental, que ve en el rule of law -con el que lo identifica- una idea moral. El primer camino es muy exigente debido a sus presupuestos éticos, pero el segundo parece demasiado frágil, porque en el concepto de derecho hay otros aspectos que el rule of law por sí solo no logra capturar si no de una manera vagamente exigente. Me refiero, sobre todo, a la propiedad de la justicia. Es cierto que el rule of law prefigura una forma de asociación humana guiada por reglas públicas aplicadas con imparcialidad, pero una sociedad justa requiere mucho más. Cabe mencionar que en ausencia del rule of law, la obligatoriedad de la regla jurídica se pone en discusión, pero lo es también por un defecto de justicia, aun si se respeta el rule of law.

Por lo tanto, debemos entender que, incluso si queremos seguir el camino minimalista en la formación del concepto de derecho, se necesita incluir en el caso elemental de derecho, junto al rule of law, también la pretensión de justicia (o de no injusticia); ${ }^{25}$ o, si queremos, una promesa de justicia, ${ }^{26}$ que cada regla jurídica lleva inevitablemente en sí misma en referencia a su contenido. Obviamente no quiero decir que por esto mismo la regla jurídica sea justa, porque eso sería una forma de iuspositivismo ideológico. Un reclamo puede ser infundado y una promesa no ser cumplida. Quizás, sea más correcto usar la definición de Radbruch (Wilk, 1950, p. 75) según la cual el derecho es esa realidad cuyo sentido es el de la búsqueda de la justicia. Solo quiero decir que la falta de justicia constituye un problema serio para la plena obligatoriedad de la regla jurídica.

24 Cfr. Fallon (1997, pp. 24-36). El constitutional rule of law sigue siendo siempre un modelo formal y, por lo tanto, no debe confundirse con la rights conception de Dworkin ni tampoco con la de Allan (2001). Ambas son concepciones sustanciales del rule of law.

25 Sobre el claim to correctness cfr., obviamente, Alexy (2017, pp. 314-341). Aquí se nota que tal afirmación es adelantada necesariamente por el derecho, al igual que la afirmación de verdad es adelantada necesariamente por la ciencia; y la de la belleza, por el arte. 
Sin embargo, esto significa que pertenece a la naturaleza del derecho, junto con el rule of law, y distinto de aquel, el tener que ser justo, ${ }^{27}$ o normativamente justificado, para que sus intérpretes busquen los significados de las reglas jurídicas que mejor cumplan con este reclamo, es decir, en la medida de lo posible, sobre la base de los materiales jurídicos existentes. Una regla jurídica injusta es defectuosa no solo desde el punto de vista moral, sino también -y eso es lo que aquí importa- desde el punto de vista jurídico. Además, si la obediencia ya no está motivada por la creencia en la rectitud o en la razonabilidad de la regla, entonces la sanción ya no estará más justificada y parecerá muy similar a un acto de mera fuerza.

Por lo tanto, podemos afirmar que el concepto de derecho, incluso si se lo entiende en un sentido minimalista, deberá contener dos dimensiones ideales: la del rule of law y la de la justicia, pero esto lleva a reconocer en la naturaleza del derecho una apertura que hace muy difícil afirmar su identidad.

Paradójicamente, parecería que el no derecho es parte esencial de la naturaleza del derecho. En efecto, a través del ideal de justicia penetran en el derecho criterios que provienen del exterior, es decir, de las otras esferas de la vida práctica, como de la moral, de la política, de la economía y, en general, de la sociedad. Mientras que el ideal del rule of law, como se ha dicho, es generado por el derecho (o, como afirma Waldron, es el presupuesto del concepto de derecho), es un ideal jurídico; el de la justicia es generado por la moral y por la política. Ciertamente, la justicia correctiva, basada en la igualdad y en la reciprocidad de las compensaciones, es aún en gran parte atribuible al rule of law (de hecho, se considera la verdadera y propia justicia "jurídica"); pero la justicia distributiva, que es una prioridad en tanto presupuesto de la justicia correctiva, viene de afuera. ${ }^{28}$ Sin embargo, está interiorizada por el derecho hasta el punto de ser parte de su naturaleza, de modo que, por ejemplo, las justificaciones morales que respaldan los derechos humanos se convierten en argumentos jurídicos, o las razones que respaldan las elecciones políticas de la justicia distributiva se convierten en ratio legis, es decir, argumentos que respaldan decisiones jurídicas.

En consecuencia, el derecho asume un carácter "reflexivo", apropiándose de juicios de valor que provienen de la sociedad y continúan a su modo su reelaboración. Es interesante notar que es la pretensión de la justicia lo que confiere al derecho esta dimensión reflexiva, la cual abre el camino a la importancia

27 Es interesante notar que etimológicamente no es ius lo que deriva de iustitia, sino, por el contrario, iustitia deriva de ius.

28 Cfr. Viola (2017, pp. 79-94). 
de la doctrina y de la jurisprudencia, y ya no el rule of law. ${ }^{29}$ Sin embargo, este último tiene la tarea de establecer límites a los intentos de realizar la justicia de modo arbitrario (Waldron, 1989, p. 94), o sea, de hacer mal el bien y, de manera constructiva, preparar el terreno de la búsqueda de justicia sustancial con una idea de sociedad basada en la igualdad, en el respeto a las personas, en la fidelidad al derecho y en el self-restraint en el uso del poder al que se le solicitan justificaciones razonables. Como ya se ha señalado, legalidad y lealtad al derecho constituyen en conjunto el rule of law entendido como práctica social.

Si el valor de la justicia es interno al concepto de derecho, a la par del valor del rule of law, entonces será posible un conflicto de valores interno al derecho. Este conflicto tiene un carácter moral, ya que es entre valores morales: por un lado, la exigencia de justicia y, por otro, el valor del orden jurídico representado por el rule of law. Sabemos que, muy a menudo, este conflicto se resuelve a favor de este último, confirmando la importancia de un orden estable que sería amenazado por la incerteza de las reglas. Pero están los casos extremos, los de la intolerable injusticia previstos por la fórmula de Radbruch. Esos demuestran que en la práctica jurídica la cuestión de la justicia está siempre presente, incluso cuando está en silencio. Está presente en el ámbito de la deliberación práctica como una razón para obedecer o no la ley y entra de este modo en competencia con otras posibles razones contradictorias.

Las razones para obedecer la ley no pueden limitarse a la necesidad de una autoridad y a su legitimidad, sino que deben extenderse a los modos y a las formas de su ejercicio y a los contenidos normativos que derivan de ella, todas "razones" (incluso las de procedimiento del rule of law) que se fundan en valores y están en el mismo nivel. Ninguna de ellas es por definición un as de espadas que anula a priori a todas las demás. ${ }^{30} \mathrm{Si}$ faltara alguna de ellas, el concepto de derecho sería deficiente en algunos aspectos. Sin embargo, el hecho de que bajo ciertas condiciones, en ausencia de justicia sustantiva, el derecho positivo pueda seguir siendo obligatorio considerando todo, muestra la exigencia de salvar tanto como sea posible la estabilidad de las relaciones sociales y las expectativas en ellas maduradas, lo que es la misma razón de ser del rule of law.

29 Simmonds (2010, pp. 1-23) enfatiza la importancia de la dimensión reflexiva del derecho, pero erróneamente la conecta con el rule of law y no con el reclamo de justicia.

30 Obviamente, aquí el objetivo polémico es la tesis de Raz sobre las exclusionary reasons, que cancelaría la deliberación jurídica. Cfr. Raz (1990, pp. 64-65) y la crítica de Rodriguez-Blanco (2014, pp. 139 . 160). 


\section{Conclusiones}

La propuesta de comenzar desde un concepto minimalista de derecho, para enriquecerlo progresivamente mediante sus implicaciones y las adquisiciones históricas y culturales, me parece más atractiva, con la condición de que, como se ha dicho, se lo haga menos ligero con la introducción de la pretensión de justicia. Eso permitiría probar la flexibilidad y el carácter incluyente frente a la evolución del derecho contemporáneo, especialmente después de su progresiva constitucionalización, que exalta sus elementos constitutivos porque refuerza la idea de justicia y exige una proyección del rule of law a nivel transnacional e internacional, especialmente en beneficio del rol de los juristas y de los jueces. El derecho no está hecho solamente de reglas, sino también de doctrina, de jurisprudencia y de principios prácticos.

En la óptica de una consideración del derecho como una obra a realizarse, que es la que se adopta aquí, la teoría jurídica no está separada de la filosofía política y moral, pero esto no significa que no tenga su autonomía relativa.

No está separado porque el sentido del derecho se inscribe dentro de la empresa general de la vida asociada, de la coordinación de las acciones sociales, de la cooperación para lograr fines comunes. El derecho contribuye a esto asegurando continuidad, estabilidad, regularidad, es decir, orden, que ya es un valor respecto al estado de naturaleza (Finnis, 2012, pp. 67-69). Pero no es un instrumento ciego, ya que participa en los fines generales de la sociedad, en las exigencias de justicia, en la defensa de los derechos y en la búsqueda del bien común. En este campo, los medios no son un instrumento, sino una especificación del fin. Por lo tanto, se puede decir que estos fines de la vida política se vuelven propios del derecho, internos a él (Ferrajoli, 2012, pp. 249-250), de modo que no cualquier orden social es por esta razón un orden propiamente jurídico, sino solo el que es correcto o no injusto.

La teoría jurídica conserva, sin embargo, su relativa autonomía, porque el derecho gobierna a su manera el conflicto de valores que es objeto de la deliberación práctica. La problemática de la interpretación de las reglas jurídicas y de su aplicación, que es la base de la obediencia a ellas, y la de la argumentación jurídica, que conduce a la deliberación y a la decisión, son sectores gobernados por vínculos y procedimientos particulares que los hacen especiales. De esta manera, la moral y la política son filtradas por el derecho y deben estar sujetas a sus condiciones de practicabilidad. Y aquí regresa la fórmula del rule of law, que es, como se ha dicho, el ideal propiamente jurídico, pero necesitado de nutrición sociopolítica. 
Por ello, en lugar de demorarse en discusiones inútiles sobre la conexión o separación entre la moral y el derecho, debería observarse con mayor atención cómo el derecho trata a la moral que trae consigo y aquella con la que participa en la práctica social. Solo que no se trata de una moralidad tout-court, sino de una visión condicionada por vínculos jurídicos y por la práctica jurisprudencial, así como por la sensibilidad ética de los operadores del derecho. ${ }^{31}$

Se configura así una ética del derecho positivo que no debe confundirse con la moralidad del derecho de la que hablaba Fuller (1969), ya que se trata de una ética material que puede ubicarse entre la moralidad positiva y la ética normativa. No es moralidad positiva porque los comportamientos sociales se miden por normas cuya validez no depende de la práctica social, sin embargo, esta ética del derecho no puede alejarse demasiado de la moralidad positiva sin perder su correspondencia social y, con eso mismo, su vitalidad. Tampoco es una ética normativa solamente por su carácter asistemático y fragmentado, sino también porque sus justificaciones están condicionadas por la razón artificial en la que consiste el derecho positivo. De todos modos, tiene algo de la ética normativa en la medida en que entre sus justificaciones están también aquellas extraídas de la razón natural, como se evidencia, por ejemplo, en la articulación jurisprudencial de los derechos humanos.

\section{Bibliografía}

Alexy, R. (2017). The Ideal Dimension of Law. En Duke, G. y George, R. (Eds.), The Cambridge Companion to Natural Law Jurisprudence (pp. 314-341). Cambridge: Cambridge University Press. https://doi.org/10.1017/9781316341544.012

Allan, T. R. S. (2001). Constitutional Justice. A Liberal Theory of the Rule of law. Oxford: Oxford University Press.

Fallon, R. (1997). "The Rule of Law" as a Concept of Constitutional Discourse. Columbia Law Review, 97(1), 1-56.

Ferrajoli, L. (2012). La teoria generale del diritto: l'oggetto, il metodo, la funzione. Rivista di Filosofia del diritto, 1(2), 229-252.

Finnis, J. (2003). Law and What I Truly Should Decide. The American Journal of Jurisprudence, 48, 107-129.

Finnis, J. (2011). Natural Law $\mathcal{E}$ Natural Rights (2a ed.). Oxford: Oxford University Press. Finnis, J. (2012). What is the Philosophy of Law? Rivista di Filosofia del diritto, 1(1), 67-78.

31 Cfr. Waldron (2009a, pp. 2-24; 2009b, pp. 69-82). 
Fuller, L. L. (1969). The Morality of Law. New Haven: Yale University Press.

Gardner, J. (2001). Legal Positivism: 51/2 Myths. The American Journal of Jurisprudence, 46(1), 199-227.

Hayek, F. A. von (1960). The Constitution of Liberty. Chicago: University of Chicago Press.

Kelsen, H. (1952). Lineamenti di dottrina pura del diritto (1934). Torino: Einaudi.

Kelsen, H. (1998). I fondamenti della democrazia (1955-56). En Kelsen, H., La democrazia. Bologna: Il Mulino.

Michelman, F. (1988). Law's Republic. The Yale Law Journal, 97(8), 1493-1537.

Pattaro E. y Roversi, C. (Eds.). (2016). A Treatise of Legal Philosophy and General Jurisprudence. Vol. 12: Legal Philosophy in the Twentieth Century: The Civil World. Tome 2: Main Orientations and Topics. Dordrecht: Springer.

Postema, G. J. (2014). Fidelity in Law's Commonwealth. En Klimchuk, D. (Ed.), Private Law and the Rule of Law (pp. 17-40). Oxford: Oxford University Press.

Raz, J. (1990). Practical Reason and Norms (1975). Princeton: Princeton University.

Rodriguez-Blanco, V. (2014). Law and Authority Under the Guise of the Good. Oxford/Portland: Hart Publishing.

Silverstein, G. (2003). Globalization and the Rule of law: "A Machine that Runs of Itself?". International Journal of Constitutional Law, 1(3), 427-445.

Simmonds, N. E. (2007). Law as a Moral Idea. Oxford: Oxford University Press.

Simmonds, N. E. (2010). Reflexivity and the Idea of Law. Jurisprudence, 1(1), 1-23.

Simmonds, N. E. (2017). Law as an Idea We Live By. En Duke, G. y George, R. (Eds.), The Cambridge Companion to Natural Law Jurisprudence (pp. 245-274). Cambridge: Cambridge University Press. https://doi.org/10.1017/9781316341544.010

Tamanaha, B. Z. (2004). On the Rule of Law. History, Politics, Theory. Cambridge: Cambridge University Press.

Viola, F. (2005). La libertà come valore politico. En Archideo, L. (Dir.), La libertad (pp. 31-55). Buenos Aires: Ciafic Ediciones.

Viola, F. (2011). Rule of Law. Il governo della legge ieri ed oggi. Torino: Giappichelli.

Viola, F. (2016a). Beni comuni e bene comune. Diritto e società, (2), 381-398.

Viola, F. (2016b). Introduction: Natural Law Theories in the 20th Century. En Pattaro E. y Roversi, C. (Eds.), A Treatise of Legal Philosophy and General Jurisprudence. Dordrecht: Springer.

Viola, F. (2017). Equità e giustizia. En Ferrari, M. (Dir.), Il problema della giustizia (pp. 79-94). Milano-Udine: Mimesis.

Waldron, J. (1989). The Rule of Law in Contemporary Liberal Theory. En Ratio Juris, 2(1), 79-96.

Waldron, J. (2000/2001). Does Law Promise Justice? Georgia State University Law Review, 17(3), $759-788$.

Waldron, J. (2006). The Core of the Case against Judicial Review. The Yale Law Journal, 115(6), 1346-1406.

Waldron, J. (2009a). Judges as moral reasoners. International Journal of Constitutional Law, 7(1), $2-24$

Waldron, J. (2009b). Refining the question about judges' moral capacity. International Journal of Constitutional Law, 7(1), 69-82.

Wilk, K. (Trad.). (1950). The Legal Philosophies of Lask, Radbruch and Dabin. Cambridge: Harvard University Press. 